\title{
Biópsia hepática no diagnóstico da intoxicação por Senecio brasiliensis (Asteraceae) em bovinos ${ }^{1}$
}

\author{
Claudio S.L. Barros ${ }^{2 *}$, Luis M.L. Castilhos ${ }^{3}$, Daniel R. Rissi ${ }^{4}$, Glaucia D. Kommers ${ }^{2}$ \\ e Raquel R. Rech ${ }^{4}$
}

\begin{abstract}
Barros C.S.L., Castilhos L.M.L., Rissi D.R., Kommers G.D. \& Rech R.R. 2007. [Liver biopsy for the diagnosis of Senecio brasiliensis (Asteraceae) poisoning in cattle.] Biópsia hepática no diagnóstico da intoxicação por Senecio brasiliensis (Asteraceae) em bovinos. Pesquisa Veterinária Brasileira 27(1):53-60. Departamento de Patologia, Universidade Federal de Santa Maria, 97105900 Santa Maria, RS, Brazil. E-mail: claudioslbarros@uol.com.br

Liver lesions caused by Senecio spp poisoning in cattle are progressive and deaths may occur many months after the plant is ingested. Laboratory tests of liver function are not always reliable indicators of subclinical affected animals. Liver biopsy could be useful to identify cattle with hepatic lesions but without clinical signs and would have also a prognostic value since it is generally believed that hepatic lesions will eventually cause liver failure and death. Such animals could be picked out by liver biopsy before clinical signs develop and be sent to slaughter, minimizing economic losses. This study was aimed to evaluate the liver biopsy as a diagnostic and prognostic tool in cases of Senecio spp. poisoning in cattle. An outbreak of Senecio brasiliensis was diagnosed in dairy calves which ingested hay contaminated by $5-10 \%$ of this Senecio species. Liver biopsy using a Menghini needle by right transthoracic approach was carried out in 135 calves that ingested the contaminated hay. Biopsed calves were followed up for 26 months after the biopsy. Seventeen biopsied calves had typical lesions of Senecio spp poisoning (positive calves) and 118 had histologically normal livers (negative calves). Hepatic lesions of positive calves included fibrosis, hepatomeglocytosis, and biliary hyperplasia. Fifteen out of the 17 positive calves died with typical clinical signs of Senecio spp poisoning within 17-149 days after the biopsy; 13 of those were necropsied and had typical gross and histopathological lesions of Senecio spp poisoning. Two positive calves were clinically normal at the end of the post-biopsy observation period. The prognostic value (sensibility) of the test was considered high since $88.23 \%$ of the positive calves died. The specificity of the test was considered very high $(99.16 \%)$ since only one of the 118 negative calves died in the observation period. In none of the biopsed calves a negative effect related to the biopsy technique was observed.
\end{abstract}

INDEX TERMS: Poisonous plants, Senecio brasiliensis, Asteraceae, liver biopsy, diseases of cattle, pathology.

RESUMO.- Lesões hepáticas causadas pela intoxicação por Senecio spp em bovinos são progressivas e mortes podem ocorrer vários meses após a ingestão da planta. Testes laboratoriais da

\footnotetext{
${ }^{1}$ Recebido em 31 de outubro de 2006.

Aceito para publicação em 16 de novembro de 2006.

Uma pequena parte dos resultados deste trabalho foi publicada na forma de carta ao Editor de Veterinary Record em 1987 (Vet. Rec. 121:382-382).

${ }^{2}$ Departamento de Patologia, Universidade Federal de Santa Maria (UFSM), 97105-900, Santa Maria, Rio Grande do Sul. *Autor para correspondência: claudioslbarros@uol.com.br

${ }^{3}$ Departamento de Clínica de Grandes Animais, UFSM. Professor aposentado.

${ }^{4}$ Programa de Pós-Graduação em Medicina Veterinária, área de concentração em Patologia Veterinária, Centro de Ciências Rurais, UFSM.
}

função hepática nem sempre são indicadores confiáveis de animais subclinicamente afetados. A biópsia hepática pode ser indicada para identificar bovinos com lesões hepáticas, mas sem sinais clínicos, e pode ter também valor prognóstico, uma vez que se acredita que as lesões hepáticas evoluam para causar insuficiência hepática e morte. Tais bovinos poderiam ser identificados pela biópsia hepática e enviados para o abate antes de desenvolverem os sinais clínicos, minimizando assim os prejuízos. Este estudo visou avaliar a biópsia hepática como um método de diagnóstico e prognóstico em casos de intoxicação por Senecio spp. em bovinos. Um surto de intoxicação por Senecio brasiliensis foi diagnosticado em bezerros de leite que haviam ingerido feno contaminado por 5-10\% dessa planta 
tóxica. Biópsia hepática com agulha de Menghini por abordagem transtorácica foi realizada em 135 bezerros que ingeriram feno contaminado. Os bezerros biopsiados foram acompanhados por um período de 26 meses após a biópsia. Dezessete bezerros biopsiados tinham lesões típicas da intoxicação por Senecio spp (bezerros positivos) e 118 tinham fígados histologicamente normais (bezerros negativos). As lesões hepáticas dos bovinos positivos incluíam fibrose, hepatomegalocitose e hiperplasia de ductos biliares. Quinze dos 17 bezerros positivos morreram com sinais clínicos típicos de intoxicação por Senecio spp. 17-149 dias após a biópsia; 13 desses foram necropsiados e apresentavam lesões macro e microscópicas típicas de intoxicação por Senecio spp. Dois bovinos positivos mantinham-se clinicamente normais ao final do período de observação pós-biópsia. O valor prognóstico (sensibilidae) do teste foi considerado alto, uma vez que $88,23 \%$ dos bezerros positivos morreram. A especificidade do teste foi considerada bastante alta (99.16\%), uma vez que apenas um dos 118 bovinos negativos na biópsia hepática morreu durante o período de observação pós-biópsia. Em nenhum bovino foi observado qualquer efeito negativo relacionado à técnica da biópsia hepática.

TERMOS DE INDEXAÇÃO: Plantas tóxicas, Senecio brasiliensis, Asteraceae, biópsia hepática, doença de bovinos, patologia.

\section{INTRODUÇÃO}

A intoxicação por plantas do gênero Senecio é uma das principais causas de morte em bovinos adultos no Rio Grande do Sul (Barros et al. 1992), sendo responsável por mais de 50\% de todas as mortes causadas por plantas no estado (Riet-Correa \& Medeiros 2001) ocasionando um prejuízo anual de US\$7,5 milhões (Karam et al. 2004). Os efeitos tóxicos de Senecio spp estão relacionados com a presença, nessas plantas, de substâncias tóxicas conhecidas pelo nome genérico de alcalóides pirrolizidínicos ou APs (Liddel et al. 1992, Méndez et al. 1990).

A ingestão de Senecio spp. causa em bovinos lesões hepáticas crônicas caracterizadas por fibrose, proliferação de ductos biliares e hepatomegalocitose (Barros et al. 1987, Driemeier et al. 1991, Driemeier \& Barros 1992). Essas lesões acabam, após períodos relativamente longos, por causar insuficiência hepática com manifestações clínicas de distúrbios neurológicos, edemas cavitários, diarréia, tenesmo e prolapso de reto. Bovinos afetados desenvolvem hiperamonemia nas fases terminais (Petrie 1987).

Quando é feito um diagnóstico de intoxicação por Senecio spp num rebanho bovino é provável que vários animais já estejam subclinicamente afetados, i.é, com lesões hepáticas, mas ainda sem apresentar sinais clínicos. Como as lesões causadas pela planta são progressivas, as mortes desses bovinos subclinicamente afetados pode ocorrer meses após a ingestão da planta ser interrompida (Tokarnia \& Döbereiner 1984, Johnson et al. 1985). Testes de função hepática são geralmente pouco confiáveis para detectar casos subclíncios da intoxicação por Senecio spp, pela simples razão de que a função hepática é normal nessa fase (Petrie 1987).
Portanto, em um surto de intoxicação por Senecio spp em bovinos, o uso da biópsia hepática pode ser indicado para identificar bovinos com lesões hepáticas, mas sem sinais clínicos. A biópsia hepática pode ter também um valor prognóstico, uma vez que bovinos afetados mais cedo ou mais tarde desenvolvem doença clínica e morrem. Tais animais poderiam ser detectados pela biópsia hepática e enviados para o matadouro antes de desenvolverem os sinais clínicos, minimizando assim as perdas econômicas.

Com o objetivo de avaliar a biópsia hepática como um teste de valor diagnóstico e prognóstico na intoxicação espontânea por Senecio spp, foi selecionado um rebanho que ingerira feno contaminado por Senecio brasiliensis e no qual já ocorrera a morte de 10 bovinos com lesões típicas da intoxicação por Senecio spp. Centro e trinta e cinco bovinos desse rebanho (dos quais 133 eram clinicamente normais) foram submetidos à biópsia hepática e acompanhados por um período de 26 meses.

\section{MATERIAL E MÉTODOS}

A coleta de dados epidemiológicos e a observação de sinais clínicos e achados de necropsia foram feitas durante visitas à propriedade onde ocorreu o surto de intoxicação por Senecio brasiliensis Less. (fam. Asteraceae), e complementados por informações do veterinário do estabelecimento. Vinte necropsias foram realizadas, duas por um dos autores (CSLB) e 18 pelo veterinário do estabelecimento. Nessas necropsias estão incluídos 6 bezerros que morreram antes da realização das biópsias e 14 bezerros que morreram em diferentes períodos após a realização da biópsia. O exame histopatológico do material de 19 dessas necropsias foi realizado no Laboratório de Patologia Veterinária (LPV) da Universidade Federal de Santa Maria (UFSM). O material colhido na necropsia era fixado em formol a $10 \%$ e processado rotineiramente para a histopatologia, corado pelo método de hematoxilina e eosina e examinado em microscopia de luz.

Biópsia hepática foi realizada em 135 bezerros; 53 bezerros foram biopsiados em 14.7.87 e 82 bezerros em 24.8.87. O método de biópsia utilizado já foi descrito em detalhe anteriormente (Braga et al. 1985). O ponto de eleição para a introdução da agulha foi o $11^{\circ}$ espaço intercostal direito, aproximadamente $20 \mathrm{~cm}$ abaixo da linha do dorso, no cruzamento de uma linha imaginária entre a tuberosidade externa do íleo e a escápula e outra linha perpendicular ao $11^{\circ}$ espaço intercostal; esse ponto corresponde à posição topográfica do lobo direito do fígado (Fig.1). Após tricotomia e antissepsia do campo com álcool iodado a agulha de biópsia era introduzida no fígado por acesso percutâneo e transtorácico. Em um dia de trabalho com dois turnos de aproximadamente 4 horas cada foram testados 80 bovinos, o que dá uma média de 6 minutos por bovino.

Os fragmentos de fígado obtidos eram aproximadamente cilíndricos e tinham cerca de $0,5-1,5 \mathrm{~cm}$ de comprimento por $0,1 \mathrm{~cm}$ de espessura. Esses fragmentos eram fixados em formol a $10 \%$ e processados rotineiramente para a histopatologia da mesma forma que o material de necropsia e examinados em microscopia de luz. Bezerros eram considerados "positivos" se o exame dos fragmentos hepáticos revelassem pelo menos duas dessas três alterações: hepatomegalocitose, fibrose e hiperplasia de ductos biliares. Bezerros cujos fígados não apresentassem essas lesões eram considerados "negativos". Porções da ração e do substituto de leite (pó) usado na alimentação dos bezerros foram examinados para aflatoxina. 


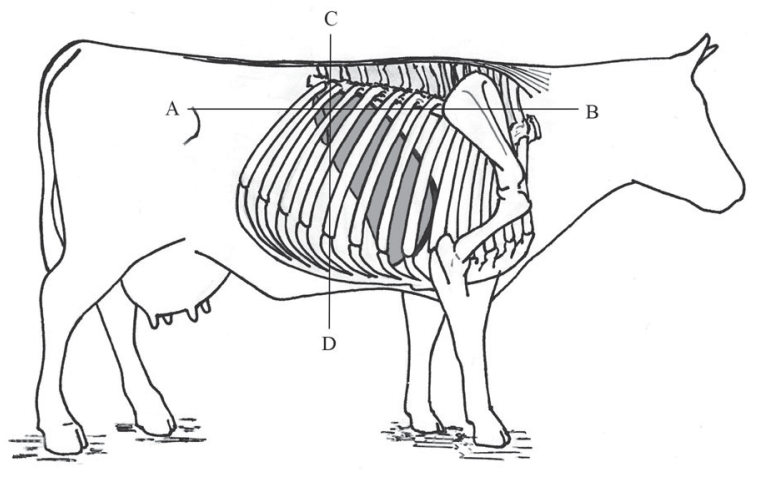

Fig 1. Diagrama mostrando o ponto para a introdução da agulha de biópsia. É escolhido um ponto no $11^{\circ}$ espaço intercostal direito, cerca de $20 \mathrm{~cm}$ abaixo da linha do dorso, no cruzamento de duas linhas imaginárias: uma que vai da tuberosidade do íleo à escápula (A-B) e outra perpendicular ao $11^{\circ}$ espaço intercostal.

\section{RESULTADOS}

Os casos ocorreram em 1987 em uma propriedade localizada no município de Jóia, RS. A propriedade tinha cerca de 6.000 ha e destinava-se inteiramente à produção de leite, com cerca de 2.000 bovinos Holandês $\mathrm{P} \& \mathrm{~B}$. A média de nascimentos era de 40 bezerros por mês ao longo do ano. Após mamarem o colostro os bezerros eram colocados em gaiolas de ferro ou em baias individuais onde ficavam até aproximadamente 120 dias de vida. Ali, desde o início lhes era ofertada a seguinte alimentação: feno de capim Rhodes (Chlorys gayana), substituto de leite diluído imediatamente antes de ser colocado nos bebedouros e ração peletizada para bezerros.

$\mathrm{O}$ feno havia sido colhido em fevereiro e oferecido aos bezerros a partir de março do mesmo ano. Parte do feno era dada como alimentação no cocho e parte (a parte pior) é tranformada em cama para os bezerros. Após 120 dias de vida, os bezerros eram transferidos para uma cabanha onde ficavam até cerca de 6 meses de idade. Em todos esses estágios, a alimentação era sempre a mesma. Inicialmente os bezerros ingeriam apenas o leite, mas ao redor de 20-30 dias já consumiam um pouco de feno e ração. $O$ exame do feno revelou contaminação de 5-10\% por Senecio brasiliensis. Uma inspeção na lavoura (feita em julho de 1987) onde havia sido colhido o capim Rhodes para a fenação revelou infestação por $S$. brasileinsis. Os resultados para exames de aflatoxina realizados no leite e na ração consumidos pelos animais foram negativos.

Entre 26 de junho e 14 de julho ocorreram 10 mortes em bezerros com idades de 3-6 meses. Os sinais clínicos apresentados pelos bezerros afetados incluíam abatimento, anorexia e tenesmo retal acompanhados em alguns casos por prolapso retal (Fig 2). Não havia diarréia, porém houve um caso em que um bezerro expeliu moldes de fibrina pelo reto. Não havia febre e a morte ocorria em 2-7 dias após o aparecimento dos sinais clínicos, com exceção de um caso, em que a evolução foi de aproximadamente 20 dias; esse bezerro mostrou também sinais clínicos de distúrbios nervosos. Seis bezerros foram necropsiados (Quadro 1). Os principais achados consistiam de cadáveres de bezerros em mau estado nutricional, fígado endurecido e com cápsula espessa; esse espessamento da cápsula dava um aspecto grisáceo à superfície do órgão. Edema gelatinoso do mesentério (principalmente da Ansa spiralis do cólon) e das pregas do coagulador era observado na maioria dos casos; edema da parede da vesícula biliar e ascite ocorriam ocasionalmente.

Microscopicamente, as principais lesões eram localizadas no fígado e consistiam de graus variáveis de fibrose hepática, proliferação de ductos biliares e hepatomegalocitose (Fig.3). Em um bezerro em que o cérebro foi examinado havia lesões de status spongiosus, principalmente próxima da interface da substância branca com a substância cinzenta. Essas lesões consistiam de vacúolos de $5-30 \mu \mathrm{m}$ de diâmetro localizados principalmente na substância subcortical do telencéfalo.

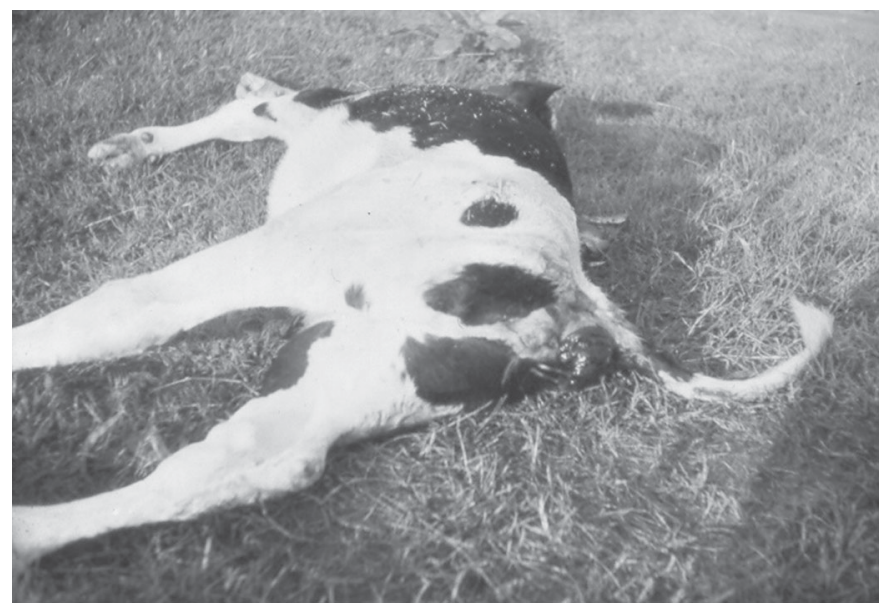

Fig 2. Bovino 583 (Vn-139-87) com prolapso de reto nas fases terminais da intoxicação por Senecio brasiliensis.

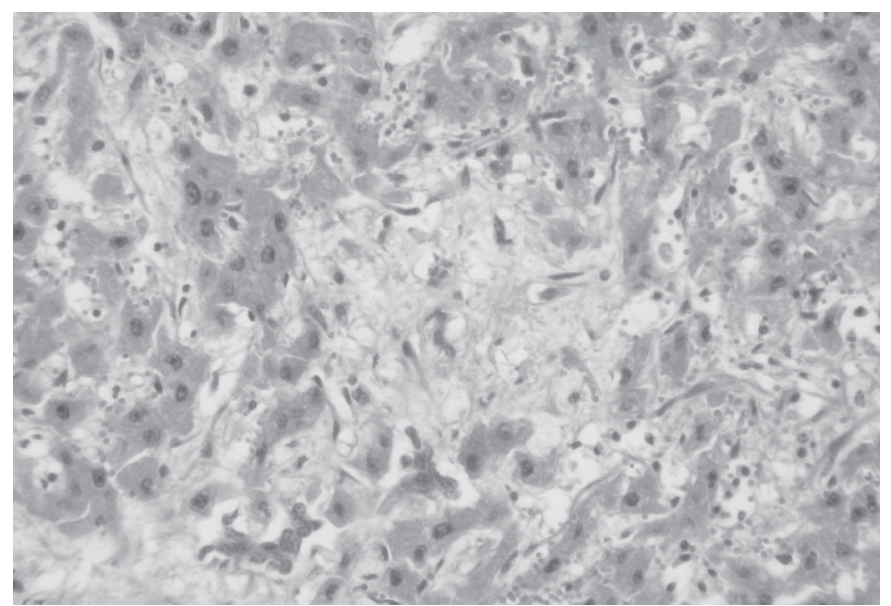

Fig 3. Bovino 583 (Vn-139-87). Aspecto histológico do fígado na intoxicação por Senecio brasiliensis. Observam-se graus moderados de fibrose, proliferação de ductos biliares e hepatomegalocitose. HE, obj.20. 
Quadro 1. Dados de seis bezerros intoxicados por ingestão de feno contaminado por Senecio brasiliensis ${ }^{\mathrm{a}}$

\begin{tabular}{|c|c|c|c|c|c|c|c|}
\hline $\begin{array}{l}\text { Bovino } \mathrm{n}^{\mathrm{o}} / \\
\text { Protocolo }\end{array}$ & Sexo & $\begin{array}{l}\text { Idade } \\
\text { (meses) } \\
o \text { início da } \\
\text { ingestão } \\
\text { do feno e } \\
\text { a morte }^{\mathrm{c}} \\
\end{array}$ & $\begin{array}{l}\text { Dias decor- } \\
\text { ridos entre }\end{array}$ & Sinais clínicos & $\begin{array}{l}\text { Evolução } \\
\text { (dias) }\end{array}$ & Achados de necropsia & Exame histológico \\
\hline Não se aplica & $\mathrm{F}^{\mathrm{d}}$ & 3 & 82 & $\begin{array}{l}\text { Abatimento, anore-, } \\
\text { xia, tenesmo }\end{array}$ & 2 & $\begin{array}{l}\text { Fígado endurecido e com cápsula } \\
\text { acinzentada, edema gelatinoso do } \\
\text { mesentério e das pregas do } \\
\text { abomaso }\end{array}$ & Não realizado \\
\hline $574 / V-253-87$ & $\mathrm{M}^{\mathrm{e}}$ & 3 & 72 & $\begin{array}{l}\text { Abatimento, anore- } \\
\text { xia, tenesmo, prolap- } \\
\text { so de reto }\end{array}$ & 3 & $\begin{array}{l}\text { Fígado endurecido e com cápsula } \\
\text { acinzentada, edema da parede da } \\
\text { vesícula biliar, ascite, edema do } \\
\text { mesentério e das pregas do } \\
\text { abomaso }\end{array}$ & $\begin{array}{l}\text { Examinados fígado e abomaso. Fígado: } \\
\text { fibrose }(++f) \text {, hiperplasia dos ductos } \\
\text { biliares }(++) \text {, megalocitose }(++) \text {. } \\
\text { Abomaso: mucosa recoberta por fibrina } \\
\text { e neutrófios; edema da submucosa } \\
(+++g)\end{array}$ \\
\hline $576 / V-255-87$ & M & 3 & 72 & $\begin{array}{l}\text { Abatimento, anorexia, } \\
\text { prolapso de reto }\end{array}$ & 3 & $\begin{array}{l}\text { Fígado endurecido e com cápsula } \\
\text { acinzentada, edema da parede da } \\
\text { vesícula biliar, ascite, edema do } \\
\text { mesentério e das pregas do } \\
\text { abomaso }\end{array}$ & $\begin{array}{l}\text { Examinados fígado e abomaso. Fígado: } \\
\text { fibrose }(+++) \text {, hiperplasia dos ductos } \\
\text { biliares }(++) \text {, megalocitose }(++) \text {. } \\
\text { Abomaso: mucosa recoberta por fibrina } \\
\text { e neutrófios; edema da submucosa } \\
(+++)\end{array}$ \\
\hline $682 / \mathrm{Vn}-130-87^{\mathrm{h}}$ & M & 4 & 71 & $\begin{array}{l}\text { Abatimento, anorexia, } \\
\text { prolapso de reto. Ex- } \\
\text { peliu moldes de fibri- } \\
\text { na pelo reto }\end{array}$ & 3 & $\begin{array}{l}\text { Atrofia gelatinosa da gordura, } \\
\text { fígado endurecido e com cápsula } \\
\text { acinzentada,hidropericárdio, } \\
\text { ascite, edema do mesentério e das } \\
\text { pregas do abomaso e edema } \\
\text { pulmonar }\end{array}$ & $\begin{array}{l}\text { Examinados fígado, linfonodos } \\
\text { mesentéricos, coração, intestino } \\
\text { delgado, abomaso, e pulmão. Fígado: } \\
\text { fibrose }(++) \text {, hiperplasia dos ductos } \\
\text { biliares }(++) \text {, megalocitose }(++) \text {. } \\
\text { Pulmão: broncopneumonia de aspiração. } \\
\text { Intestino delgado e abomaso: edema da } \\
\text { submuscosa }(++) \text {. Linfonodos: edema }\end{array}$ \\
\hline 1474/V-289-87 & $\mathrm{F}$ & 3 & 62 & $\begin{array}{l}\text { Abatimento, anorexia, } \\
\text { tenesmo retal, batia } \\
\text { com a cabeça na gaiola } \\
\text { como se mostrasse dor }\end{array}$ & 20 & $\begin{array}{l}\text { Fígado endurecido e com cápsula } \\
\text { acinzentada, ascite }\end{array}$ & $\begin{array}{l}\text { Examinados fígado, pulmão, coração, } \\
\text { encéfalo, abomaso e rim. Fígado: fibrose } \\
(+++) \text {, hiperplasia ductal }(++) \text {, } \\
\text { megalocitose }(+++) \text {. Encéfalo: } \\
\text { degeneração esponjosa. Pulmão: } \\
\text { congestão e edema. Coração: sem } \\
\text { alterações }\end{array}$ \\
\hline $1443 / V-368-87$ & $\mathrm{~F}$ & 6 & 67 & $\begin{array}{l}\text { Abatimento, anorexia, } \\
\text { tenesmo }\end{array}$ & 7 & $\begin{array}{l}\text { Fígado endurecido e pálido, edema } \\
\text { do mesentério e das pregas do } \\
\text { abomaso }\end{array}$ & $\begin{array}{l}\text { Examinados fígado e rim. Fígado: fibrose } \\
(++) \text {, hiperplasia ductal }(++) \text {, } \\
\text { megalocitose }(++) \text {, venoclusão }\end{array}$ \\
\hline
\end{tabular}

aNesse período foram ainda relatadas, neste estabelecimento, quatro mortes de terneiros de 3-4 meses com sinais clínicos semelhantes. Esses animais não foram necropsiados e por isso não constam no Quadro. ${ }^{\mathrm{b}} \mathrm{Os}$ casos identificados por $\mathrm{V}$ são de bovinos cujas necropsias foram realizadas pelo veterinário do estabelecimento e que tiveram as amostras remetidas ao Laboratório de Patologia Veterinária (LPV) da Universidade Federal de Santa Maria (UFSM). O caso identificado por $\mathrm{Vn}$ indica necropsia realizada por um dos autores (CSLB). 'Segundo informação do veterinário do estabelecimento e do tratador dos bezerros, o feno era oferecido aos bezerros desde o nascimento, mas os bezerros começavam a ingerir o feno com 20-30 dias de idade. A data de início da ingestão foi

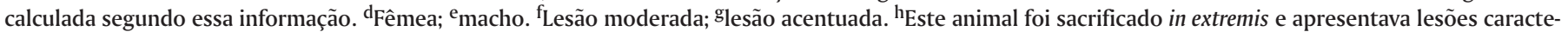
rísticas da intoxicação

Foi feito um diagnóstico de intoxicação por $S$. brasiliensis por ingestão de feno contaminado por essa planta tóxica. $\mathrm{O}$ feno contaminado foi suspenso da alimentação e substituído por feno de alfafa de boa qualidade. Cento e trinta e cinco bezerros que tinham tido acesso ao mesmo tipo de ração que os 10 bezerros que haviam morrido foram submetidos à biópsia hepática. Dezessete desses bezerros mostraram lesões de intoxicação por Senecio spp na biópsia e foram considerados positivos; 118 bezerros tinham aspecto histológico normal na biópsia hepática e foram, portanto, considerados negativos. Os achados histológicos na biópsia hepática dos bovinos positivos consistiam de fibrose, hepatomegalocitose e hiperplasia de ductos biliares. Uma lesão observada em todas as biópsias positivas foi a vacuolização do núcleo de hepatócitos, acompanhada por marginação da cromatina para a periferia nuclear; ocasionalmente observavam-se pseudoinclusões acidofílicas intranucleares. Na Figura 4 estão representadas as principais alterações encontradas nas biópsias hepáticas positivas. Dos 17 animais positivos, 15 eram clinicamente normais e dois (Bovinos 583 e 681) já mostravam sinais clínicos acentuados da intoxicação quando da realização da biópsia. Esses dois bezerros morreram no dia seguinte ao da biópsia. Dos 15 bezerros positivos e sem sinais clínicos, 13 morreram entre 17 e 149 dias após o diagnóstico da biópsia (Quadro 2). Desses bezerros, 13 foram necropsiados e apresentavam as lesões macro e microscópicas de seneciose semelhantes às observadas nos bezerros necropsiados no início do surto (Quadro 3). Nos 13 bovinos que haviam sido 
Quadro 2 Dados dos bezerros com lesões características da intoxicação por Senecio spp. na biópsia hepática ${ }^{a}$

\begin{tabular}{cccccc}
\hline $\begin{array}{c}\text { Bovino } \\
\text { no. }\end{array}$ & $\begin{array}{c}\text { Protocolo } \\
\text { LPV/UFSM }^{\text {b }}\end{array}$ & $\begin{array}{c}\text { Idade } \\
\text { (meses) }\end{array}$ & $\begin{array}{c}\text { Resultado } \\
\text { da biópsia }\end{array}$ & $\begin{array}{c}\text { Tempo decor- } \\
\text { rido entre a } \\
\text { biópsia e a } \\
\text { morte (dias) }\end{array}$ & $\begin{array}{c}\text { Necropsia/Lesões } \\
\text { da intoxicação } \\
\text { por Senecio spp }\end{array}$ \\
\hline 583 & Vn-139-87 & 3 & $+^{\text {c }}$ & 1 & Sim/Sim \\
681 & V-366-87 & 4 & ++ & 1 & Sim/Sim \\
1464 & V-370-87 & 4 & ++ & 17 & Sim/Sim \\
585 & V-545-87 & 3 & ++ & 25 & Sim/Sim \\
568 & V-386-87 & 5 & ++ & 25 & Sim/Sim \\
685 & V-387-87 & 3 & ++ & 27 & Sim/Sim \\
1455 & V-385-87 & 4 & ++ & 28 & Sim/Sim \\
1475 & V-391-87 & 4 & ++ & 29 & Sim/Sim \\
1463 & V-366-87 & 4 & ++ & 29 & Sim/Sim \\
1466 & V-548-87 & 4 & ++ & 57 & Sim/Sim \\
1460 & V-507-87 & 4 & ++ & 58 & Sim/Sim \\
689 & V-367-87 & 3 & ++ & 65 & Sim/Sim \\
565 & V-555-87 & 5 & ++ & 86 & Sim/Sim \\
1461 & - & 4 & ++ & 144 & Não/indeterminado \\
1479 & - & 3 & ++ & 149 & Não/indeterminado \\
1457 & - & 4 & $+^{\mathrm{d}}$ & Não morreu & Não \\
1481 & - & 3 & + & Não morreu & Não \\
& & & & &
\end{tabular}

a Um total de 135 bezerros foram submetidos à biópsia; os restantes 118 não constam da tabela porque foram negativos e permaneceram clinicamente normais até o final do período de observação ( 26 meses após a biópsia). 0 bezerro 634 ( 8 meses de idade) foi interpretado como negativo na biópsia hepática, mas morreu 30 dias após a realização da biópsia e na necropsia e histopatologia apresentava alterações características da intoxicação por Senecio spp.

bLaboratório de Patologia Veterinária da Universidade Federal de Santa Maria.

'Lesão moderada.

desão leve.

Fig 4. Bovino 1460 (V-507-87). Aspectos histológicos da biópsia hepática. (A) Já em menor aumento pode-se observar proliferação de ductos biliares e hepatomegalocitose. HE, obj.10. (B) Maior aumento de A. HE, obj.20. (C) Maior aumento da figura anterior mostrando núcleo vazio com cromatina marginada (seta). HE, obj.40.

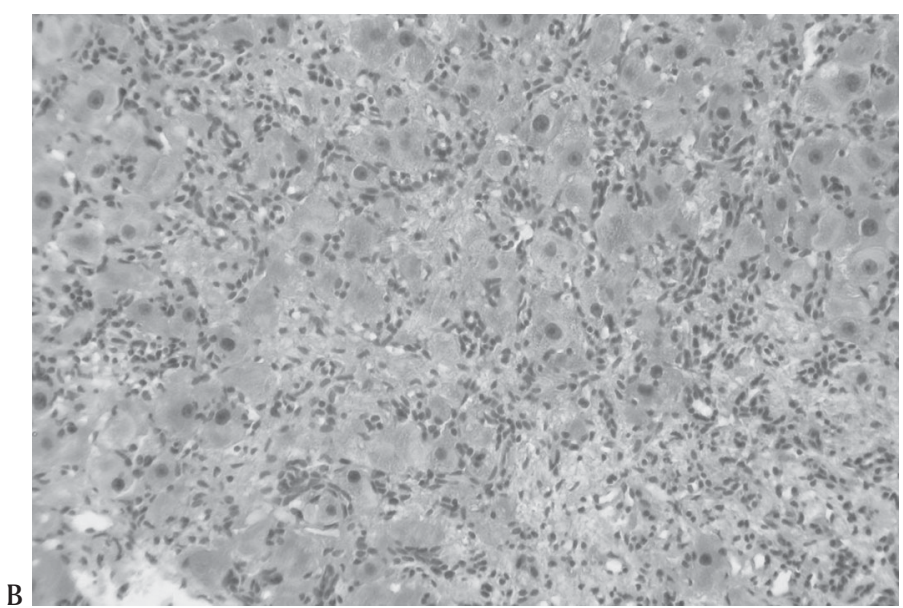

biopsiados era possível observar-se junto à borda do lobo direito do fígado, um foco de cerca de $0,2-03 \mathrm{~cm}$ de diâmetro deprimido na superfície do fígado. Esse foco correspondia a cicatriz da biópsia e na histopatologia era observado como uma trajeto de fibrose de alguns centímetros de profundidade. Dois bezerros (Bovinos 1461 e 1479) morreram com sinais clínicos de intoxicação, mas não foram necropsiados. Dois bovinos que tinham lesões caracteríticas de seneciose na biópsia (Bovinos 1457 e 1481) permanecem clinicamente normais por dois anos e dois meses após a biópsia, a partir de quando não foram mais acompanhados. No último exame essas duas novilhas estavam prenhes. Durante o tempo de acompanhamento, o peso desses bovinos foi normal e comparável ao dos animais negativos. Dos 118 bezerros considerados negativos apenas um (Bovino 634) morreu no período deste estudo, 30 dias após a realização da biópsia. Esse bovino foi necropsiado e apresentava lesões macro e microscópicas características da intoxicação por APs (Quadro 3).

\section{DISCUSSÃO}

O diagnóstico de intoxicação por Senecio brasiliensis nos bovinos deste surto baseou-se nos sinais clínicos, achados de necropsia e na histopatologia característica da intoxicação por APs (McLean 1970). S. brasiliensis já foi demonstrado experimentalmente como tóxico para bovinos (Tokarnia \&
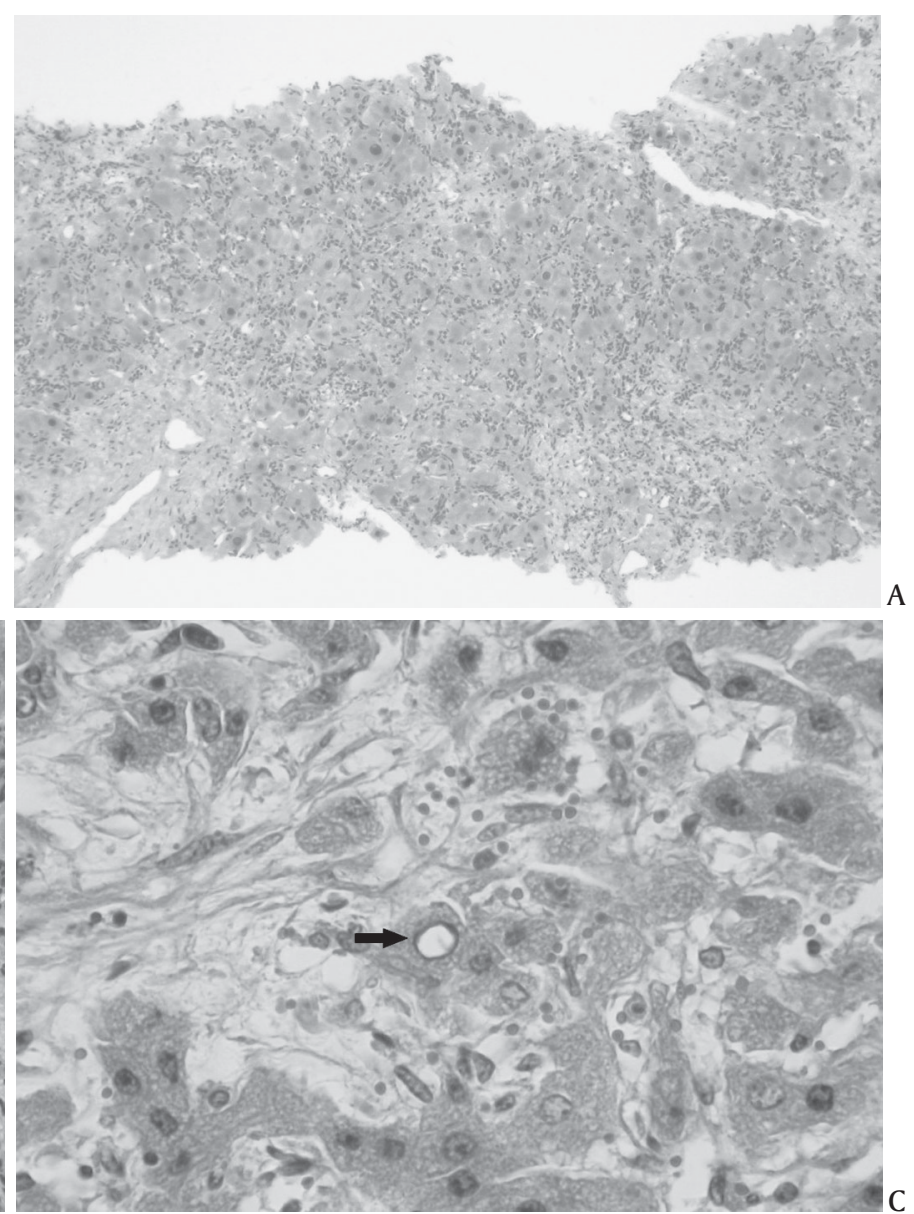
Quadro 3. Dados dos bezerros biopsiados e que morreram de foram necropsiados no períoodo de observação (26 meses) após a biópsia

\begin{tabular}{|c|c|c|c|c|}
\hline $\begin{array}{l}\text { Bovino } \\
\text { no. }\end{array}$ & $\begin{array}{l}\text { Protocolo } \\
\text { LPV/UFSM }^{\mathrm{a}}\end{array}$ & Achados de necropsia & $\begin{array}{l}\text { Material colhido na necropsia e } \\
\text { examinado histologicamente }\end{array}$ & Histopatologiab \\
\hline 583 & Vn-139-87 & $\begin{array}{l}\text { Prolapso de reto, fígado endurecido }(++) \text {, coloração } \\
\text { alaranjada, arborização fibrosa na superfície de corte, } \\
\text { edema da parede da vesícula biliar, ascite, edema do } \\
\text { mesentério e das pregas do abomaso }\end{array}$ & $\begin{array}{l}\text { Fígado, coração, linfonodos, in- } \\
\text { testino, rim, adrenal e encéfalo }\end{array}$ & $\begin{array}{l}\text { Fibrose }(++) \text {, hepatomegalocitose, } \\
\text { hiperplasia de ductos biliares, status } \\
\text { spongiosus }(+++) \text { no encéfalo }\end{array}$ \\
\hline 681 & V-366-87 & $\begin{array}{l}\text { Fígado endurecido }(++) \text {, coloração alaranjada, edema } \\
\text { da parede da vesícula biliar, arborização fibrosa na } \\
\text { superfície de corte, edema do mesentério e das pregas } \\
\text { do abomaso }\end{array}$ & Fígado & $\begin{array}{l}\text { Fibrose }(++) \text {, hepatomegalocitose, } \\
\text { hiperplasia de ductos biliares }\end{array}$ \\
\hline 1464 & V-370-87 & $\begin{array}{l}\text { Fígado endurecido }(+++) \text {, coloração cinza violácea, } \\
\text { edema da parede da vesícula biliar, edema do } \\
\text { mesentério e das pregas do abomaso }\end{array}$ & Fígado, coração, pulmão, rim e & $\begin{array}{l}\text { Fibrose }(++) \text {, hepatomegalocitose, } \\
\text { hiperplasia de ductos biliares, status } \\
\text { spongiosus }(+) \text { no encéfalo }\end{array}$ \\
\hline 585 & V-545-87 & $\begin{array}{l}\text { Prolapso de reto, fígado endurecido }(++) \text {, coloração } \\
\text { cinza violácea, edema da parede da vesícula biliar, } \\
\text { edema do mesentério e das pregas do abomaso }\end{array}$ & Fígado, coração, rim e encéfalo & $\begin{array}{l}\text { Fibrose }(++) \text {, hepatomegalocitose, } \\
\text { hiperplasia de ductos biliares, status } \\
\text { spongiosus }(+++) \text { no encéfalo }\end{array}$ \\
\hline 568 & V-386-87 & $\begin{array}{l}\text { Fígado endurecido }(+++) \text {, coloração cinza violácea, } \\
\text { arborização fibrosa na superfície de corte, ascite, edema } \\
\text { da parede da vesícula biliar, edema do mesentério e } \\
\text { das pregas do abomaso }\end{array}$ & $\begin{array}{l}\text { Fígado, coração, linfonodos } \\
\text { pulmão, rim e encéfalo }\end{array}$ & $\begin{array}{l}\text { Fibrose }(++) \text {, hepatomegalocitose, } \\
\text { hiperplasia de ductos biliares, status } \\
\text { spongiosus }(++) \text { no encéfalo }\end{array}$ \\
\hline 685 & V-387-87 & $\begin{array}{l}\text { Prolapso de reto, fígado endurecido }(+++) \text {, coloração } \\
\text { cinza violácea, edema do mesentério e das pregas do } \\
\text { abomaso }\end{array}$ & Fígado, coração e rim & $\begin{array}{l}\text { Fibrose }(++) \text {, hepatomegalocitose, } \\
\text { hiperplasia de ductos biliares }\end{array}$ \\
\hline 1455 & V-385-87 & $\begin{array}{l}\text { Prolapso de reto, fígado endurecido }(++) \text {, coloração } \\
\text { alaranjada, edema do mesentério e das pregas do } \\
\text { abomaso }\end{array}$ & $\begin{array}{l}\text { Fígado, vesícula bilar, coração, } \\
\text { pulmão, rim e encéfalo }\end{array}$ & $\begin{array}{l}\text { Fibrose }(++) \text {, hepatomegalocitose, } \\
\text { hiperplasia de ductos biliaresstatus } \\
\text { spongiosus }(+++) \text { no encéfalo }\end{array}$ \\
\hline 1475 & V-391-87 & $\begin{array}{l}\text { Fígado endurecido }(+++) \text {, coloração cinza violácea, } \\
\text { ascite, edema do mesentério e das pregas do abomaso }\end{array}$ & $\begin{array}{l}\text { Fígado, coração, abomaso, pul- } \\
\text { mão, rim e encéfalo }\end{array}$ & $\begin{array}{l}\text { Fibrose }(+++) \text {, hepatomegalocitose, } \\
\text { hiperplasia de ductos biliares, status } \\
\text { spongiosus }(+) \text { no encéfalo }\end{array}$ \\
\hline 1463 & V-366-87 & $\begin{array}{l}\text { Fígado endurecido }(+++) \text {, coloração branco creme, } \\
\text { edema do mesentério e das pregas do abomaso }\end{array}$ & $\begin{array}{l}\text { Fígado, coração, pulmão, rim e } \\
\text { encéfalo }\end{array}$ & $\begin{array}{l}\text { Fibrose }(++) \text {, hepatomegalocitose, } \\
\text { hiperplasia de ductos biliares, status } \\
\text { spongiosus }(++) \text { no encéfalo }\end{array}$ \\
\hline 634 & V-547-87 & $\begin{array}{l}\text { Prolapso de reto, fígado endurecido }(+++) \text {, coloração } \\
\text { branco creme, edema da parede da vesícula biliar, } \\
\text { edema do mesentério e das pregas do abomaso }\end{array}$ & $\begin{array}{l}\text { Fígado, coração, pulmão, rim, be- } \\
\text { xiga e encéfalo }\end{array}$ & $\begin{array}{l}\text { Fibrose }(+++) \text {, hepatomegalocitose, } \\
\text { hiperplasia de ductos biliares, status } \\
\text { spongiosus }(+++) \text { no encéfalo }\end{array}$ \\
\hline 1466 & V-548-87 & $\begin{array}{l}\text { Fígado endurecido }(+++) \text {, coloração alaranjada, } \\
\text { edema do mesentério e das pregas do abomaso }\end{array}$ & $\begin{array}{l}\text { Fígado, vesícula bilar, pulmão, } \\
\text { rim e encéfalo }\end{array}$ & $\begin{array}{l}\text { Fibrose }(+++) \text { com metaplasia óssea do } \\
\text { tecido fibroso, hepatomegalocitose, } \\
\text { hiperplasia de ductos biliares estatus } \\
\text { spongiosus }(++) \text { no encéfalo }\end{array}$ \\
\hline 1460 & V-507-87 & $\begin{array}{l}\text { Fígado endurecido }(+++) \text {, coloração cinza violácea, } \\
\text { edema do mesentério e das pregas do abomaso }\end{array}$ & $\begin{array}{l}\text { Fígado, coração, baço, rim, bexi- } \\
\text { ga e encéfalo }\end{array}$ & $\begin{array}{l}\text { Fibrose }(+++) \text { com metaplasia óssea do } \\
\text { tecido fibroso, hepatomegalocitose, } \\
\text { hiperplasia de ductos biliares e status } \\
\text { spongiosus }(++) \text { no encéfalo }\end{array}$ \\
\hline 689 & V-367-87 & $\begin{array}{l}\text { Fígado endurecido }(+++) \text {, coloração alaranjada, ascite } \\
\text { edema do mesentério e das pregas do abomaso }\end{array}$ & $\begin{array}{l}\text { Fígado, abomaso, pulmão, rim, ure- } \\
\text { ter, bexiga e encéfalo }\end{array}$ & $\begin{array}{l}\text { Fibrose }(+++) \text {, hepatomegalocitose, } \\
\text { hiperplasia de ductos biliares e status } \\
\text { spongiosus }(+++) \text { no encéfalo }\end{array}$ \\
\hline 565 & V-555-87 & $\begin{array}{l}\text { Fígado endurecido }(+++) \text {, coloração alaranjada, ascite } \\
\text { edema do mesentério e das pregas do abomaso }\end{array}$ & $\begin{array}{l}\text { Fígado, vesícula biliar, coração, } \\
\text { pulmão e rim }\end{array}$ & $\begin{array}{l}\text { Fibrose }(+++) \text {, hepatomegalocitose, } \\
\text { hiperplasia de ductos biliares }\end{array}$ \\
\hline
\end{tabular}

aLaboratório de Patologia Veterinária da Universidade Federal de Santa Maria, ${ }^{\text {b }}+$ lesão leve, ++ lesão moderada, +++ lesão acentuada.

Döbereiner 1984) e ovinos (Barros et al. 1989) e surtos da intoxicação espontânea por $S$. brasiliensis já foram relatados em ambas as espécies (Barros et al. 1987, Barros et al. 1992, Ilha et al. 2001). Além disso, os APs integerrimina e retrorsina na poroporção de $0,31 \%$ da matéria seca foram dectados nessa planta tóxica (Méndez et al. 1990). Evidência adicional para confirmar o diagnóstico de intoxicação por $S$. brasiliensis nos bovinos deste estudo foi a presença da planta tóxica seca no feno com que os animais eram alimentados. Já foi demonstrado que $S$. brasiliensis mantém sua toxidez mesmo quando secado (Tokarnia \& Döbereiner 1984, Barros et al. 1989).
Embora bovinos jovens sejam susceptíveis aos efeitos de aflatoxinas e as lesões hepáticas de aflatoxicose crônica sejam semelhantes às da intoxicação por APs (Cullen 2007), a hipótese de aflatoxicose crônica nesse caso pôde ser afastada pelo resultado negativo para aflatoxina na análise da ração comercial e do substituto de leite que compunham a dieta dos bezerros. É pouco provável que o feno seja um substrato adequado para o crescimento dos fungos produtores de aflatoxinas.

De aproximadamente 145 bezerros que tiveram acesso ao feno contaminado, 26 morreram com quadro de intoxicação 
por Senecio spp. e dois bezerros, aparentemente afetados, se recuperaram; isso dá coeficientes de morbidade, mortalidade e letalidade respectivamente de 19,3, 17,9 e 92,8\%. Muitos bezerros $(80,7 \%)$ que potencialmente tinham acesso à ração contaminada não adoeceram; isso pode ser explicado pelo fato de que a distribuição da planta tóxica no feno provavelmente não fosse homogênea e muitos bezerros poderiam ter recebido partes com pouca ou nenhuma planta tóxica. Outros fatores podem explicar a variação entre animais no grau de insulto hepático frente a mesma dose de APs (Johnson et al. 1983); esses incluem (i) a velocidade de excreção e absorção dos APs no trato digestivo, (ii) a variação na quantidade de oxidases de função mista (responsáveis pela conversão, no fígado, de APs em pirróis tóxicos) e (iii) a velocidade de formação de pirróis.

Os casos casos de intoxicação por Senecio spp no Brasil são geralmente relatados em bovinos adultos em pastoreio (Tokarnia et al. 2000, Karam et al. 2004, Masuda et al. 2005). O surto descrito aqui ocorreu em bezerros de 3-6 meses de idade devido ao manejo. O feno ficava à disposição dos bezerros desde o primeiro dia de vida, mas segundo o tratador e o proprietário do estabelecimento, os animais iniciavam a ingestão do feno ao redor de 20-30 dias de idade; como o mais novo dos bezerros a desenvolver a intoxicação tinha 3 meses, o tempo mínimo de ingestão de pequenas quantidade da planta foi de 2 meses.

A intoxicação por Senecio spp. é uma importante causa de perdas em bovinos no Rio Grande do sul, onde a doença é apontada como a segunda causa de morte em bovinos, sendo superada apenas pela tristeza parasitária (Riet-Correa \& Medeiros 2001, Karam et al. 2004). Dados do nosso laboratório sugerem que, pelo menos na região de influência do LPV/UFSM, a intoxicação por Senecio spp seja a primeira causa de morte em bovinos. Em surtos dessa intoxicação, a principal preocupação do proprietário é quanto à determinação de quantos bovinos irão ainda morrer após o diagnóstico inicial. Bovinos com lesões hepáticas subclínicas da intoxicação por Senecio spp podem desenvolver os sinais clínicos e morrer vários meses após terem cessado a ingestão da planta (Betty \& Markson 1954, Lloyd 1957, Tokarnia \& Döbereiner 1984, Johnson et al. 1985, Monaghan \& Sheahan 1987).

Testes laboratoriais de função hepática são ocasionalmente recomendados para o diagnóstico de casos subclínicos de intoxicação por Senecio spp (Lloyd 1957), mas esses testes, na grande maioria das vezes, não são indicados para confirmar casos subclínicos (Petrie 1987). Além disso, esses testes detectam insuficiência hepática de qualquer causa e não são específicos para insuficiência hepática induzida pela intoxicação por Senecio spp (Lloyd 1957). A biópsia hepática pode ser indicada para a detecção de casos subclínicos de intoxicação por Senecio spp, pois as lesões hepáticas nessa intoxicação são difusas e não é necessária orientação para a biópsia. Além disso, o tempo necessário para a realização da biópsia hepática é pouco mais do que o empregado para a aplicação de uma injeção e permite que vários bovinos sejam testados em um rebanho.

As lesões hepáticas dos bovinos positivos incluíram graus variados de fibrose, hepatomegalocitose e hiperplasia de ductos bilaires. A vacuolização do núcleo é descrita como "núcleo em anel" e considerada como umas das lesões mais precoces na intoxicação por Senecio jacobaea e S. ridelli (Johnson et al. 1983, 1985) e foi também observada principalmente ao redor dos espaços-porta do fígado de bovinos intoxicados experimentalmente por S. oxyphyllus (Driemeier \& Barros 1992). $\mathrm{O}$ valor prognóstico (sensibilidade) da biópsia hepática foi considerado alto, uma vez que $88,23 \%$ dos bezerros positivos morreram da intoxicação 17-149 dias após a biópsia. A especificidade do teste foi considerada bastante alta $(99,16 \%)$, uma vez que apenas um dos 118 bovinos negativos na biópsia hepática morreu 30 dias após a realização do procedimento; na necropsia e na histopatologia desse bezerro havia alterações características da intoxicação por Senecio spp. Uma possível explicação para esse fato é que as lesões fossem muito incipientes para serem detectadas na biópsia. É provável que isso ocorra ocasionalmente quando se realiza biópsia hepática em um rebanho sob risco, como foi observado em um equiino intoxicado experimentalmente por S. brasiliensis (Barros 1990, observações não publicadas); a administração da planta foi suspensa no dia em que foi realizada a última biópsia no eqüino e, embora nenhuma lesão fosse detectada na biópsia, o eqüino morreu vários meses após a biópsia com lesões características da intoxicação.

Em nenhum bovino foi observado qualquer efeito negativo relacionado à técnica da biópsia hepática. Dois bovinos considerados positivos na biópsia hepática permaneciam clinicamente normais 26 meses pós a biópsia. Isso leva a concluir que nem todos os casos que têm lesões de intoxicação por Senecio spp na biópsia desenvolvem insuficiência hepática. Casos de recuperação semelhantes já haviam sido relatados (Monaghan \& Sheahan 1987).

Em conclusão, o método de biópsia hepática tem sensibilidade e especificidade suficientes para ser indicado na deteç̧ão de casos subclínicos de intoxicação por Senecio spp. Isso permitirá uma recomendação ao proprietário que encaminhe os casos positivos para o abate. $\mathrm{O}$ método de biópsia pode ser aplicado para estudos epidemiológicos, pois permite estimar a verdadeira extensão de um surto de intoxicação por Senecio spp.

\section{REFERÊNCIAS}

Barros C.S.L. 1990. Dados não publicados (Departamento de Patologia, Universidade Federal de Santa Maria, 97105-900 Santa Maria, RS)

Barros C.S.L., Driemeier D., Pilati C., Barros S.S. \& Castilhos L.M.L. 1992. Senecio spp. poisoning in cattle in southern Brazil. Vet. Human Toxicol. 34:241-246.

Barros C.S.L., Metzdorf L., Santos M.N., Barros S.S. \& Peixoto P.V. 1989. Intoxicação experimental por Senecio brasiliensis (Compositae) em ovinos. Pesq. Vet. Bras. 9:55-67.

Barros C.S.L., Metzdorf L.L. \& Peixoto P.V. 1987. Ocorrência de surtos da intoxicação por Senecio brasiliensis (Compositae) em bovinos no Rio Grande do Sul. Pesq. Vet. Bras. 7:101-107.

Barros C.S.L., Metzdorf L.L., Santos M.N. \& Peixoto P.V. 1989. Intoxicação experimental por Senecio brasiliensis (Compositae) em ovinos. Pesq. Vet. Bras. 8:110-116.

Betty D.C. \& Markson L.M. 1954. Liver biopsy in the diagnosis of ragwort (Senecio jacobeae) poisoning in a herd of cattle. Vet. Rec. 66:398-400. 
Braga M.M., Castilhos L.M.L. \& Santos M.N. 1985. Biópsia hepática em bovinos: proposta de nova técnica. Revta Centro Ciênc. Rurais, Santa Maria, 15:79-88.

Cullen J.M. 2007. Liver, biliary system and exocrine pancreas, p.393-461. In: McGavin M.D. \& Zachary J.F. (ed.), Pathologic Basis of Veterinary Disease. 4th ed., Mosby Elsevier, St Louis. 1476p.

Driemeier D. \& Barros C.S.L. 1992. Intoxicação experimental por Senecio oxyphyllus (Compositae) em bovinos. Pesq. Vet. Bras. 12:33-42.

Driemeier D., Barros C.S.L. \& Pilati C. 1991. Seneciose em bovinos. Hora Vet., Porto Alegre, 10:23-30.

Ilha M.R.S, Loretti A.P., Barros S.S. \& Barros C.S.L. 2001. Intoxicação espontânea por Senecio brasiliensis (Asteraceae) em ovinos. Pesq. Vet. Bras. 21:123-138.

Johnson E.A. \& Smart R.A. 1983. Effects on cattle and their calves of tansy ragwort (Senecio jacobaea) fed in early gestation. Am. J. Vet. Res. 44:12151219.

Johnson E.A., Molyneux R.J. \& Stuart L.D. 1985. Toxicity of Riddell's groundsel (Senecio ridelli) to cattle. Am. J. Vet. Res. 46:577-582

Karam F.S.C., Soares M.P., Haraguchi M., Riet-Correa F., Méndez M.C. \& Jarenkow J.A. 2004. Aspectos epidemiológicos da seneciose na região sul do Rio Grande do Sul 24:191-198.

Liddel J.R., Stermitz F.R. \& Barros C.S.L. 1992. Pyrrolizidine alkaloids from
Senecio oxyphyllus, a Brazilian poisonous plant. Bioch. System. Ecol. 20:393393.

Lloyd J.R. 1957. The use of a liver function test in the prognosis of ragwort poisoning in cattle. Vet Rec. 69:623-625.

Masuda, E.K., Rissi D.R., Barros R.R. \& Barros C.S.L. 2005. Epidemiologia, sinais clínicos e patologia da intoxicação por Senecio spp. em bovinos no Rio Grande do Sul. Arq. Bras. Med. Vet. Zoot. (Supl.) 57:65.

McLean E.K. 1970. The toxic actions of pyrrolizidine (Senecio) alkaloids. Pharm. Rev. 33:429-483.

Méndez M.C., Riet-Correa F., Schild A.L. \& Martz W. 1990. Intoxicação experimental por cinco espécies de Senecio em bovinos e aves. Pesq. Vet. Bras. 10:63-69.

Monaghan M.L. \& Sheahan B.J. 1987. Liver biopsy in ragwort poisoning. Vet. Rec. 11:274.

Petrie I. 1987. Differential diagnosis of diarrhea in adult cattle. Practice 9:50.

Riet-Correa F. \& Medeiros R.M.T. 2001. Intoxicações por plantas no Brasil e no Uruguai: importância econômica, controle e riscos para a saúde pública. Pesq. Vet. Bras. 21:38-42.

Tokarnia C.H. \& Döbereiner J. 1984. Intoxicação experimental por Senecio brasiliensis (Compositae) em bovinos. Pesq. Vet. Bras. 4:39-65.

Tokarnia C.H., Döbereiner J. \& Peixoto P.V. 2000. Plantas Tóxicas do Brasil. Editora Helianthus, Rio de Janeiro, p.98-109. 